\title{
Immobilization of Protein A on SAMs for the elaboration of immunosensors
}

\author{
Elisabeth Briand ${ }^{\mathrm{a}}$, Michèle Salmain ${ }^{\mathrm{b}}$, Chantal Compère ${ }^{\mathrm{c}}$ and Claire-Marie Pradier ${ }^{\mathrm{a},{ }^{*}}$
}

\author{
aLaboratoire de Réactivité de Surface, UMR CNRS 7609, Université Pierre et Marie Curie, 4 Place \\ Jussieu, 75005 Paris, France \\ ${ }^{b}$ Laboratoire de Chimie et Biochimie des Complexes Moléculaires, UMR CNRS 7576, Ecole Nationale \\ Supérieure de Chimie de Paris, 11 Rue Pierre et Marie Curie, 75231 Paris Cedex 05, France \\ 'Service Interfaces et Capteurs, IFREMER, BP 70, 29280 Plouzané, France \\ *: Corresponding author : pradier@ccr.jussieu.fr
}

\begin{abstract}
:
Binary mixtures of 11-mercaptoundecanoic acid (MUA) and other thiols of various lengths and terminal functions were chemisorbed on gold-coated surfaces via S-Au bonds to form mixed self-assembled monolayers (SAMs). Several values of the mole fraction of MUA in the thiol mixtures were tested and the structure and composition of the resulted thin films were characterized by X-ray photoelectron spectroscopy (XPS) and polarization modulation infrared reflection-absorption spectroscopy (PMIRRAS). The results made it clear that co-adsorption of MUA with thiols of similar chain length led to well-ordered monolayers whereas the co-adsorption of MUA with shorter thiols yielded less crystallinelike thin films, but with more reactive carboxylic acid terminal groups. This criterion appeared decisive for efficient covalent binding of Staphylococcus aureus Protein A (PrA), a protein that displays high affinity for the constant fragment $(\mathrm{Fc})$ of antibodies of the IgG type from various mammal species. The ability of immobilized Protein $A$ to recognize and bind a model IgG appeared to be optimal for the mixed SAM of MUA and the short-chain, $\omega$-hydroxythiol 6-mercaptohexanol in the proportion 1-3.
\end{abstract}

Keywords: Self-assembled monolayers; Gold; Protein A; Antibody; PM-IRRAS 
Organic thiols and disulfides and to a lesser extent sulfides spontaneously chemisorb from solutions onto noble metals such as gold and silver to form stable monolayer films in a very reproducible way [1-4]. These films, often referred as self-assembled monolayers (SAMs), have a densely packed, crystalline-like structure, provided that the alkyl chain of the sulfur-containing molecules is sufficiently long. Thanks to this feature, materials with new surface properties can be designed for the controlled binding of biomolecules by properly selecting the headgroup functionality of the alkyl thiol [5].

Further tailoring of surface properties can be achieved by co-assembling two thiols to form so-called mixed SAMs. However, self-assembling of thiolate mixtures onto gold substrates addresses new questions, such as the molecular composition of the resulting monolayers which may differ from that of the solution, the molecular structure of the film in relation with the occurrence of intermolecular interactions between the thiolate components, order/disorder and phase segregation phenomena. Mixed SAMs with random surface distribution of the thiolate components are built when the thiols have similar chain lengths and end groups of similar sizes [6-9]. Conversely, phase segregation was evidenced to occur when the alkyl chain lengths differed by more than three carbon atoms [7,10-14].

Recently, SAMs resulting from the co-adsorption of two different thiols (i.e. mixed SAMs) have been shown to promote protein adsorption thanks to multiple chemical functionalities on the surfaces and decrease steric hindrance around the functional tails [15]. Complex or mixed SAMs have been successfully used to immobilize bioligands such as biotin [16-18], nickel complexes [19] or benzenesulfonamide [20,21]. They also served to immobilize a range of proteins, including glucose oxidase [22], cytochrome C [23], antibodies $[24,25]$, human serum albumin [26], laccase [27] and streptavidin [28]. The stability and the molecular recognition properties of these proteins, once immobilized on mixed SAMs, were significantly improved as compared to pure SAMs adlayers.

One of the most advanced applications of SAMs on gold is the design of biosensors [29]. The strategy chosen to create the sensing layer should enable to control both the amount and the orientation of the bioreceptor on the transducer while preserving its bioactivity. Numerous strategies have been designed to immobilize antibodies for immunosensor build up, among which direct physisorption [30-32], covalent binding [30,33-38], and affinity binding via the biotin / avidin couple [39-41]. We chose another, less classical, route based on the high affinity of Staphylococcus aureus Protein A (PrA) for antibodies.

Staphylococcus aureus Protein A binds specifically to the Fc region of immunoglobulin molecules, especially immunoglobulin $G$ (IgG) of many mammal species 
[42]. This feature has been extensively used for antibody affinity purification [43]. Several examples of immunosensing devices based on the immobilization of specific antibodies via a layer of PrA have been reported. The benefit is a proper orientation of the bound antibody on surfaces [44] and easy immunosensor regeneration [45]. Some of the previously published immobilization procedures relied on the direct physisorption of PrA onto the metallic substrates [37,46-53] while others rely on the formation of a covalent bond between an amine of PrA and a reactive function of the pre-coated organic layer [30,54-60].

Focusing on the elaboration of smart immunosensors, the above-mentioned properties of mixed SAMs were applied to immobilize PrA on planar gold substrates. In the present work, several reactive mixed SAMs were prepared by co-adsorption of binary mixtures of the long chain, $\omega$-carboxyl thiol 11-mercaptoudecanoic acid, (MUA) and several “diluting” thiols of various chain lengths and terminal groups. In the first series of experiments, the diluting thiols were 11-mercaptoundecanol $(\mathrm{C} 11 \mathrm{OH})$, n-decanethiol (C9CH3), 6-mercaptohexanol $(\mathrm{C} 6 \mathrm{OH})$ or n-hexanethiol $(\mathrm{C} 5 \mathrm{CH} 3)$ at a constant mole fraction of MUA, $\chi(\mathrm{MUA})_{\text {soln }}$ equal to 0.5. In the second series of experiments, mixed SAMs of MUA and either decanethiol or 6mercaptohexanol were prepared from solutions containing the two thiols with variable $\chi(\mathrm{MUA})_{\text {soln }}$. The mole fraction of MUA on the surface, $\chi(\mathrm{MUA})_{\text {surf, }}$ estimated from XPS data, was correlated to the mole fraction of MUA in the starting solution $\chi(\mathrm{MUA})_{\text {soln }}$. Immobilization of PrA was achieved by conversion of the carboxylic acid functions into $\mathrm{N}$ hydroxysuccinimide esters by reaction with $N$-hydroxysuccinimide (NHS) in the presence of a water-soluble carbodiimide (EDC), followed by reaction with Protein A (Scheme 1).

The binding capacity of the resulting PrA layers towards rabbit IgG (rIgG) was eventually examined and compared. Polarization modulation infrared reflection-absorption spectroscopy (PM-IRRAS) and X-ray photoelectron spectroscopy (XPS), two complementary surface analytical techniques, were combined to characterize the gold surfaces at the successive functionalization steps. 


\section{EXPERIMENTAL SECTION}

\section{Chemicals}

n-Decanethiol (C9CH3), n-hexanethiol (C5CH3), 11-mercaptoundecanoic acid (MUA), 11-mercaptoundecanol (C11OH), 6-mercaptohexanol $\quad(\mathrm{C6OH}), \quad N$ hydroxysuccinimide (NHS), $N$-(3-dimethylaminopropyl)- $N$ '-ethylcarbodiimide hydrochloride (EDC) were purchased from Aldrich (Saint-Quentin Fallavier, France). Rabbit IgG (rIgG) and bovine serum albumin (BSA) were purchased from Sigma (Saint-Quentin Fallavier, France), recombinant Protein A (PrA) was purchased from Pierce (Perbio, Brebières, France). All solvents were reagent-grade. Reagents were used without any further purification. Experiments were carried out at room temperature.

\section{Formation of the mixed SAMs}

Glass substrates $(11 \times 11 \mathrm{~mm})$ coated successively with a $50 \AA$ thick layer of chromium and a $200 \AA$ thick layer of gold were purchased from Arrandee (Werther, Germany). The gold-coated substrates were annealed by a brief passage in a flame to ensure a good crystallinity of the topmost layers, as recommended by the company, and rinsed in a bath of absolute ethanol during 15 min before adsorption. The substrates were immersed in freshly prepared binary mixtures of the above-cited thiols in absolute ethanol at a total thiol concentration of $10 \mathrm{mM}$ for $3 \mathrm{~h}$ as recommended Hobara et al. [8] to ensure an optimal homogeneity of the mixed adsorbed layer. After thorough rinsing in ethanol and drying under a flow of clean air, the sample surfaces were analyzed in the air by PM-IRRAS and under vacuum by XPS.

\section{Covalent immobilization of PrA}

The gold-coated substrates were treated with a solution of NHS (20 mM) and EDC (10 $\mathrm{mM})$ in water for $2 \mathrm{~h}$. The substrates were immersed in a solution of PrA (10 mg/L) in $10 \mathrm{mM}$ PBS $\mathrm{pH} 7.4$ for $2 \mathrm{~h}$. The residual NHS esters were blocked by treatment with $1 \mathrm{M}$ ethanolamine $\mathrm{pH} 9.0$ for $20 \mathrm{~min}$. Finally, the substrates were immersed in a $1 \%(\mathrm{w} / \mathrm{v})$ solution of BSA in $10 \mathrm{mM}$ PBS pH 7.4 for $2 \mathrm{~h}$. Before each new treatment, the substrates were extensively rinsed in pure water and dried. 


\section{Binding of antibody}

PrA-coated substrates were immersed in a solution of $\operatorname{rIgG}(0.07,0.1$ or $1 \mathrm{~g} / \mathrm{L})$ in PBS for $2 \mathrm{~h}$. The substrates were rinsed extensively with water and dried with a flow of air before analysis.

\section{Characterization of the monolayers}

$X$-ray Photoelectron Spectroscopy. XPS analysis was performed using a VG 220i XL system. High-resolution XPS conditions have been fixed, i.e. constant analyses energy mode with $20 \mathrm{eV}$ as pass energy, and an $\mathrm{Al} \mathrm{K}_{\alpha} \mathrm{X}$-ray (1486.6 eV) excitation giving high-resolution spectra. The take-off angle (angle between the surface and the direction of the analyser) was equal to $90^{\circ}$. The following core level regions were analyzed: O 1s, C 1s, S 2 p and N 1s. The binding energies were calibrated against the binding energies of $\mathrm{Au}_{4 \mathrm{f}_{7 / 2}}$ and $\mathrm{Cu} 2 \mathrm{p}_{3 / 2}$; with this calibration and after correction of the charge effect, the low energy carbon peak, attributed to hydrocarbon contamination, was set at $284.8 \pm 0.1 \mathrm{eV}$. The sensitivity factors of the elements were taken from ref. [61], the transmission factor was checked to be constant over the analyzed range. For the fitting procedure, no constraint was applied to the initial binding energy values, the full width at half maximum (FWHM) was set at $1.4 \pm 0.2 \mathrm{eV}$ for the carbon and nitrogen contributions, $1.6 \pm 0.2 \mathrm{eV}$ for the oxygen contributions, with a Gaussian/Lorentzian ratio, G/L, equal to 60/40.

PM-IRRAS measurements. The FTIR instrument used in our experiment is a commercial NICOLET Nexus spectrometer. The external beam was focused on the sample with a mirror, at an optimal incident angle of $75^{\circ}$. A ZnSe grid polarizer and a ZnSe photoelastic modulator, modulating the incident beam between $\mathrm{p}$ and s polarisations (HINDS Instruments, PEM 90, modulation frequency $=37 \mathrm{kHz}$ ), were placed prior to the sample. The light reflected at the sample was then focussed on a nitrogen-cooled MCT detector. The sum and difference interferograms were processed and Fourier-transformed to yield the differential reflectivity $\Delta \mathrm{R} / \mathrm{R}=(\mathrm{Rp}-\mathrm{Rs}) /(\mathrm{Rp}+\mathrm{Rs})$ which is the PM-IRRAS signal [62,63]. An important advantage of the PM-IRRAS technique, over the classical IRRAS mode of analysis, is that the signal is directly extracted from the $\Delta \mathrm{R} / \mathrm{R}$ data, avoiding a reference spectrum to be recorded on a bare sample. All the spectra reported below were recorded at $8 \mathrm{~cm}^{-1}$ resolution by coadding 64 scans. 


\section{RESULTS}

\section{Characterization of the mixed MUA-containing SAMs}

Having in mind that the reactivity of the organic film is highly dependent on its hydrophobic / hydrophilic character, and that the chain length and the tail group may influence the layer structure, mixed SAMs of MUA and either $\mathrm{C} 11 \mathrm{OH}$ or $\mathrm{C} 9 \mathrm{CH} 3$ (thiols of similar chain) or MUA and either $\mathrm{C} 6 \mathrm{OH}$ or $\mathrm{C} 5 \mathrm{CH} 3$ (thiol chain lengths differing by 5 methylene units) were prepared and characterized by appropriate surface analytical techniques. The mole fraction of MUA, $\chi(\mathrm{MUA})_{\text {soln, }}$ was kept constant and equal to 0.5. Fig. 1 depicts the PM-IRRAS spectra of the gold samples after rinsing and drying. No band was ever observed at $2550 \mathrm{~cm}^{-1}$, the expected $\mathrm{vS}-\mathrm{H}$ wavenumber, implying that all thiols were mainly bound to gold by formation of Au-S bonds. Intense bands were observed at 2850-2925 $\mathrm{cm}^{-1}$ and assigned to the symmetric and asymmetric $v \mathrm{C}-\mathrm{H}$ modes of the alkyl chains. The features between 1800 and $1300 \mathrm{~cm}^{-1}$ differed from one spectrum to another. Three of them displayed a more or less intense band at c.a. $1720 \mathrm{~cm}^{-1}$, which we readily assigned to the stretching mode of the carbonyl group of the carboxylic acid of MUA thiolates. Interestingly, the mixed SAM of $\mathrm{C} 11 \mathrm{OH}$ and MUA lacked this band. Instead, a broad and intense feature centred at $1610 \mathrm{~cm}^{-1}$ was observed. This band was assigned to the symmetric stretching mode of the carbonyl in carboxylate functions. The associated asymmetric vibration mode expected around $1400 \mathrm{~cm}^{-1}$ was observed concomitantly but was partially superimposed with the $\mathrm{CH}_{2}$ scissoring mode at c.a. $1450 \mathrm{~cm}^{-1}$. The $1610 \mathrm{~cm}^{-1}$ band was also observed on the IR spectrum of the mixed SAM of $\mathrm{C} 6 \mathrm{OH}$ and MUA while it was absent on the spectra of the mixed SAMs including $\mathrm{C5CH3}$ and $\mathrm{C9CH3}$. Thus, the presence of a terminal hydroxyl group on the diluting thiol seemed to induce deprotonation of the carboxyl group, especially when the two thiols had the same length, possibly because of favorable hydrogen bonding. Conversely, coadsorption of MUA with hydrophobic thiols kept the carboxyl tail group in its acidic form.

Two types of thiols were selected to be co-adsorbed with MUA: one having a hydrophobic end group (C9CH3) and one having a hydrophilic one ; for the latter, the above results led us to prefer the $\mathrm{C} 6 \mathrm{OH}$ in order to avoid any perturbing interaction between $\mathrm{COOH}$ and $\mathrm{OH}$ end groups.

A series of gold-coated substrates were treated by solutions containing MUA and C9CH3 with $\chi(\mathrm{MUA})_{\text {soln }}$ equal to $0,0.25,0.5,0.75$ and 1 . PM-IRRAS spectra were recorded 
for all samples and the area of the $\mathrm{C}=\mathrm{O}$ stretch at $1720 \mathrm{~cm}^{-1}$ was measured as a probe of the MUA surface concentration. The $v \mathrm{C}=\mathrm{O}$ band area increased with $\chi(\mathrm{MUA})_{\text {soln }}$ following an almost linear trend (Fig. 2a), within the experimental error on area measurements and the possible influence of the terminal group orientation on the band intensity. In the $\mathrm{vC}$-H region (Fig. 2b), the progressive disappearance of the two weak bands at 2962 and $2877 \mathrm{~cm}^{-1}$, assigned to the symmetric and asymmetric $\mathrm{C}-\mathrm{H}$ stretches of the terminal $\mathrm{CH}_{3}$ group of ndecanethiol, was observed when $\chi(\mathrm{MUA})_{\text {soln }}$ increased. The chemical composition of these mixed SAMs was further studied by high resolution XPS. The most valuable quantitative information was provided by the $\mathrm{O}$ 1s core level spectra, since only MUA contains oxygen atoms. The normalized I(O 1s) / I(Au 4f) ratio was plotted as a function of $\chi(\mathrm{MUA})_{\text {soln }}$ (Fig. 3). The data points seemed to indicate that $\chi(\mathrm{MUA})_{\text {surf }}$ was slightly lower than $\chi(\mathrm{MUA})_{\text {soln }}$ over the range tested, which is in good agreement with previously published data [64]. The low amount of residual oxygen on the gold substrate covered with $\mathrm{C} 9 \mathrm{CH} 3$ originated from adventitious contamination of the metallic substrate as also observed by analysis of "clean" gold surface.

Another series of gold-coated substrates was treated by solutions containing MUA and $\mathrm{C} 6 \mathrm{OH}$ with $\chi(\mathrm{MUA})_{\text {soln }}$ equal to $0,0.25,0.5,0.75$ and 1 , and analyzed by PM-IRRAS. The area of the $v \mathrm{C}=\mathrm{O}$ band at $1720 \mathrm{~cm}^{-1}$ was plotted as a function of $\chi(\mathrm{MUA})_{\text {soln }}$ (Fig. 4a), after having checked that the band areas ratio of the acidic to the basic forms was constant. It increased linearly with $\chi(\mathrm{MUA})_{\text {soln. }}$. The $\mathrm{vC}-\mathrm{H}$ region (Fig. 4b) brought additional information; first, the intensity of the asymmetric and symmetric $\mathrm{vC}-\mathrm{H}$ of the methylene groups increased with $\chi(\mathrm{MUA})_{\text {sol, }}$ as would be expected for an increase of the total number of methylene units when $\chi$ (MUA) increases. Moreover, the two bands progressively shifted towards lower wavenumbers, down to 2850 and $2919 \mathrm{~cm}^{-1}$ for $\chi(\mathrm{MUA})_{\text {soln }}=1$ which are typical of crystalline-like thin films [2]. Complementary XPS analyses performed on these mixed SAMs were not conclusive since this time both thiols contain oxygen.

\section{Reactivity of the mixed SAMs}

Covalent binding of $\operatorname{PrA}$

Covalent linkage of any protein to a carboxylic acid terminated SAM is most conveniently done by first converting the carboxylic acid functions into $\mathrm{N}$ - 
hydroxysuccinimide esters [20,24,65,66]. A series of mixed SAMs of MUA and C9CH3 $\left(\chi(\mathrm{MUA})_{\text {soln }}\right.$ being equal to $\left.0.25,0.50,0.75\right)$ together with a homogeneous SAM of MUA were treated with an aqueous solution of NHS and EDC and submitted to PM-IRRAS analysis (Fig. 5a, $\left.\chi(\mathrm{MUA})_{\text {soln }}=0.25\right)$. A band centred at $1746 \mathrm{~cm}^{-1}$ attributed to the ester group was now observed on the spectra, indicating that at least partial esterification of the carboxylic acid functions of the films had occurred. In parallel, mixed SAMs of MUA and C6OH were also treated with NHS and EDC. The PM-IRRAS spectrum of the surfaces (Fig. 6a, $\left.\chi(\mathrm{MUA})_{\text {soln }}=0.25\right)$ displayed three bands at 1820,1790 and $1746 \mathrm{~cm}^{-1}$, which are characteristic of the $N$-hydroxysuccinimide ester moiety [65,67]. Comparison of the intensity of the ester bands made it clear that, at the same $\chi(\mathrm{MUA})_{\text {soln, }}$, the surface coverage in ester groups was much higher when the diluting thiol was $\mathrm{C6OH}$. Each of the activated mixed SAMs was treated with a buffered solution of PrA and the surface IR spectra were again recorded (Fig. 5b and 6b). Two prominent bands at 1660 and $1550 \mathrm{~cm}^{-1}$ were now observed, which were readily assigned to the amide I and amide II bands of the protein peptide bonds. This was accompanied with a significant decrease of the intensity of the $1746 \mathrm{~cm}^{-1}$ band (28 $\%$ and $47 \%$ for the mixed SAMs containing $\mathrm{C} 9 \mathrm{CH} 3$ and $\mathrm{C} 6 \mathrm{OH}$ at $\chi(\mathrm{MUA})_{\text {soln }}=0.25$, respectively). To determine the optimal conditions of chemisorption for PrA, the ratio of the amide I+II bands area over the $1746 \mathrm{~cm}^{-1}$ band area was calculated for each of the mixed SAMs including C9CH3. It was shown to be the greatest for the mole fraction of MUA equal to 0.25 (table 1). The same trend was observed for the mixed SAMs containing $\mathrm{C} 6 \mathrm{OH}$.

Deactivation of the remaining ester groups was achieved by treatment in a solution of ethanolamine at high concentration. Indeed the $1746 \mathrm{~cm}^{-1}$ band disappeared (fig. 5c and 6c) and instead a weak feature at $1732 \mathrm{~cm}^{-1}$ was observed which was attributed to the carboxylic acid groups of PrA.

\section{Antibody recognition}

These results prompted us to focus our subsequent studies on the mixed SAMs with $\chi(\mathrm{MUA})_{\text {soln }}=0.25$ and the two systems, MUA and C6OH and MUA and C9CH3, were systematically compared. Gold substrates covered by the mixed SAMs and activated by NHS and EDC were successively treated by PrA, BSA and eventually IIgG and analysed by PMIRRAS after each step. The corresponding PM-IRRAS spectra are shown in fig. 7. Let us note 
first that the amount of bound PrA was much larger for the mixed SAM containing C9CH3, despite a lower amount of surface reactive NHS ester groups as seen above.

The behaviour of the PrA-coated gold substrates towards non specific binding of a protein, namely BSA, was then studied (Scheme 2). BSA was chosen because it is a classical blocking agent in solid-phase immunoassays [33]. Moreover, this protein displays a strong affinity for various types of surfaces [68].

An appreciable amount of BSA (26\% increase of the area of the amide I+II bands) did bind only when the adlayer was formed from the MUA and $\mathrm{C} 6 \mathrm{OH}$ mixture. Then, the same samples were immersed in buffered solutions of IIgG (which served as model antibody) at 0.07, 0.1 and $1 \mathrm{~g} / \mathrm{L}$. A $2.2( \pm 0.1)$ fold increase of the amide I+II bands area was measured when the adlayer was the MUA / C9CH3 mixed SAM whatever the concentration of rIgG. Conversely, a concentration-dependent increase of the amide I+II bands area was observed when the adlayer was the mixed SAM of MUA and $\mathrm{C} 6 \mathrm{OH}$, with a 3.3-fold increase for the $0.07 \mathrm{~g} / \mathrm{L}$ rIgG solution, a 4.5 -fold increase for the $0.1 \mathrm{~g} / \mathrm{L}$ and a 6.3 -fold increase for the $1 \mathrm{~g} / \mathrm{L}$ rIgG solution. The capacity of PrA immobilized on the mixed SAM including $\mathrm{C6OH}$ to bind rIgG was confirmed by XPS results as discussed in the following section.

Gold-coated substrates successively covered with the MUA/C6OH mixed SAM, PrA and rIgG were analyzed by XPS (three different samples). High resolution spectra were recorded for $\mathrm{Au} 4 \mathrm{f}, \mathrm{C} 1 \mathrm{~s}, \mathrm{O}$ 1s, $\mathrm{N}$ 1s and S 2p core levels. The sulfur peak was centred at BE $=162.3 \mathrm{eV}$, a value characteristic of S-Au bonds [69]; it was weak, hardly detectable after PrA, and rIgG binding. The O 1s peak, centered at $532.3 \mathrm{eV}$ was rather broad $(\mathrm{FWHM})=2.6$ $\mathrm{eV}$ ) in accordance with the presence of several types of oxygen in the film. The high resolution C 1s spectrum for the mixed SAM of MUA and C6OH (Fig. 8a) was decomposed into three components, the first one at $285 \pm 0.2 \mathrm{eV}$, the second one at $286.5 \pm 0.2 \mathrm{eV}$ and the last one at $289.0 \pm 0.2 \mathrm{eV}$ corresponding to carbon in C-C, C-H bonds, in C-C-O (with a weak contribution of carbon in $\alpha$ position of the sulfur atom) and $\mathrm{O}=\mathrm{C}-\mathrm{O}$ groups respectively. Table 2 reports the relative peak intensities of the $\mathrm{C} 1 \mathrm{~s}$ individual components.

The relative amount of carbon atoms in $\mathrm{O}=\mathrm{C}-\mathrm{O}$ groups was in very good agreement with the calculated value, which confirmed that the surface mole fraction of MUA was close to the solution mole fraction. For the other types of carbon, the discrepancy between the calculated and actual relative intensities may be explained by the attenuation of the photoelectrons emitted by the carbon atoms located in the subsurface region leading to an underestimation of $\mathrm{C}$ atoms of the $\mathrm{C}-\mathrm{C}, \mathrm{C}-\mathrm{H}$ and $\mathrm{C}-\mathrm{O}$ types. 
After PrA binding, the C 1s spectrum was fitted at best with 4 contributions (Fig. 8b) following Rouxhet et al. assignments [70]: the $1^{\text {st }}$ peak, at the lowest binding energy of 284.8 $\pm 0.2 \mathrm{eV}$, is assigned to carbon bound only to $\mathrm{C}$ or $\mathrm{H}$; the $2^{\text {nd }}$ peak, at $285.8 \pm 0.2 \mathrm{eV}$, is attributed to carbon in $\mathrm{C}-\underline{\mathrm{C}}-\mathrm{N}$ bonds (i.e. mainly the $\alpha$-carbons of the protein backbone), the $3^{\text {rd }}$ peak, at $286.8 \pm 0.2 \mathrm{eV}$, to carbon in C-C-O or in aromatic groups,. The $4^{\text {th }}$ peak, at the highest binding energy of $288.6 \pm 0.2 \mathrm{eV}$, was also much broader (FWHM $=1.85 \mathrm{eV}$ instead of 1.35 for the other $\mathrm{C}$ contributions), because it now included carbons of the $\mathrm{N}-\mathrm{C}=\mathrm{O}$ and $\mathrm{O}-$ $\mathrm{C}=\mathrm{O}$ types in agreement with ref. [71]. The quantitative proportion in the different types of $\mathrm{C}$ atoms was calculated from the published sequence of PrA [72] and compared to the relative intensity of the four C 1s peak components (Table 3).

A good agreement between the calculated and experimental values was reached, except for the $\mathrm{C}-\underline{\mathrm{C}}-\mathrm{N}$ and $\mathrm{C}-\underline{\mathrm{C}}-\mathrm{O}$ types. As these $\mathrm{C}$ atom types correspond to overlapping contributions in the $\mathrm{C} 1 \mathrm{~s}$ spectrum, the measurement of their respective areas may be less precise. Another possible source of error, when considering nothing but PrA on the surface, is the detection of a weak carbon signal carbon from the underlying SAM layer. Nonetheless, this comparison provides good evidence that chemically intact PrA molecules were chemisorbed on the gold surface.

The $\mathrm{N}$ 1s spectra of the PrA and rIgG samples (Fig. 9) displayed a symmetrical peak centred at $400.9 \mathrm{eV}$, arising from $\mathrm{N}$ atoms in uncharged amines and amides [73]. The $\mathrm{N} 1 \mathrm{~s}$ peak intensity for the rIgG sample increased by a factor of 3 related to the PrA sample. Assuming that one PrA molecule is able to bind 2 IgG molecules (PrA contains 5 sequential Fc binding domains among which at least half of them are blocked by immobilization [74]), the $\mathrm{N}$ 1s peak intensity should increase by a factor of 8 as there are 4 times more nitrogen atoms in an IgG molecule than in PrA; this difference is due to the attenuation of the $\mathrm{N} 1 \mathrm{~s}$ photoelectrons through the organic layer by the underlayers and possibly to a lower binding capacity of immobilized PrA towards rIgG. Alternatively, the XPS experimental conditions applied to the sample may have cause damages to the organic layer.

Finally, the Au 4f $\mathrm{f}_{7 / 2}$ peak (centered at $84.1 \mathrm{eV}$ ) intensity was measured for the three samples and the average thickness of the organic layers (Table 4) was calculated for each of them, from the following equation.

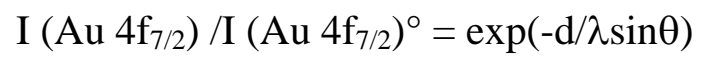

where $\mathrm{I}\left(\mathrm{Au} 4 \mathrm{f}_{7 / 2}\right) / \mathrm{I}\left(\mathrm{Au} 4 \mathrm{f}_{7 / 2}\right)^{\circ}$ is the Au 4f $\mathrm{f}_{7 / 2}$ intensity ratio, $\mathrm{d}$ is the film thickness, $\theta$ the takeoff angle, $\lambda$ the attenuation length of $\mathrm{Au} 4 \mathrm{f}_{7 / 2}$ photoelectrons through an organic layer. $\mathrm{I}(\mathrm{Au}$ 
$\left.4 \mathrm{f}_{7 / 2}\right)^{\circ}$ is the intensity of the gold peak of a bare sample, annealed and rinsed in ethanol as done before adsorption of thiols. $\lambda$ was taken equal to $42 \AA$, using the formula established by Whitesides et al. for an ordered thiolate SAM, reasonably applicable to our systems [75].

A simple calculation of the $\mathrm{N}$ 1s peak intensities, throughout the PrA and PrA+IgG organic layer of the above calculated lengths (1.63 and $6.60 \mathrm{~nm}$ respectively), leads to a ratio equal to 2.4 in relatively good agreement with the experimentally observed value equal to 3 .

\section{DISCUSSION}

\section{Chemisorption of mixed SAMs}

Co-adsorption of binary mixtures of MUA and another thiol addresses several issues as regards the structure of the resulting SAMs. The first one concerns the surface composition of the SAMs resulting from the co-adsorption of thiol mixtures. Both PM-IRRAS and XPS analyses of the mixed SAMs of MUA and C9CH3 at various $\chi(\mathrm{MUA})_{\text {soln }}$ strongly suggested that the surface fraction of MUA closely followed that in solution, i.e. $\chi(\text { MUA })_{\text {surf }} \sim$ $\chi(\mathrm{MUA})_{\text {soln }}$. As for the MUA / C6OH system, although no conclusion could be brought by XPS measurements, the IR data allow us to consider, here again, that $\chi(M U A)_{\text {surf }}$ and $\chi(\mathrm{MUA})_{\text {soln }}$ were very close.

The second issue concerns the packing of the thin films. The most useful probe to get an insight into the packing / order of the thin films was the position of the asymmetric $v \mathrm{C}-\mathrm{H}$ band of the methylene groups in the PM-IRRAS spectra [1,2,76]. Our results confirm previously published data, i.e. mixed SAMs of thiols of similar lengths such as MUA and C9CH3 were well ordered whatever $\chi(\mathrm{MUA})_{\text {surf }}(\mathrm{vC}-\mathrm{H}$ at relatively low wavenumbers). Conversely, the mixed SAM of MUA and $\mathrm{C} 6 \mathrm{OH}$ which differ by their chain length were disordered at low and intermediate $\chi(\mathrm{MUA})_{\text {surf }}$ (see Fig. $4 \mathrm{~b}$ ): the symmetric and asymmetric $\mathrm{CH}_{2}$ stretching bands shifted to lower wavenumbers when the fraction of MUA increased, indicating a progressive ordering of the layer. Accordingly, mixed SAMs of thiolates having chain lengths differing by 3 methylenes were shown to be disordered whatever the nature of the terminal moieties [9]. An additional evidence for packing disorder for the mixed SAM containing $\mathrm{C6OH}$ was provided by XPS as the layer thickness of the mixed SAM at $\chi(\mathrm{MUA})_{\text {soln }}=0.25$ was equal to $8.2 \AA$ (Table 4), which is very close to the theoretical $9 \AA$ size for full extended $\mathrm{C} 6 \mathrm{OH}$. This might indicate that the longer MUA thiolate chains were 
somewhat bent towards the shorter $\mathrm{C} 6 \mathrm{OH}$ thiolate chains, possibly forming hydrogen bonds between their respective end groups.

The third issue concerns the chemical state of the MUA carboxyl head group that was highly dependent on the nature of the diluting thiolate. Favorable hydrogen bond interactions with the hydroxyl head group of $\mathrm{C} 11 \mathrm{OH}$ led to complete deprotonation of the carboxyl group of MUA thiolate whereas no such interaction can occur with the short chain methylterminated C5CH3 and the carboxyl group of MUA chains was therefore fully protonated.

At this stage, one may wonder whether the thiolate components of these mixed SAMs are randomly distributed or phase-segregated. Considering previously published data, phase segregation is likely to occur for mixed SAMs of MUA and $\mathrm{C6OH}$ (thiols having chains that differ by more than $3 \mathrm{CH}_{2}$ groups) [77]. We indeed previously characterized $\mathrm{C6OH} / \mathrm{MUA}$ and C9CH3/MUA mixed layers, $\left(\chi(\mathrm{MUA})_{\text {soln }}=0.25\right)$ and observed protubing aggregates in the former case while an apparently homogeneous layer was imaged in the latter [78]. Nevertheless, even on C60H/MUA layers, we noticed a very good reproducibility of our results, specially the binding of PrA and rIgG. Thus the probable phase segregation had little to no influence on the reactivity of the mixed layer towards PrA and rIgG.

\section{Chemisorption of Protein A on mixed SAMs and binding affinity towards rabbit IgG}

Two mixed SAM systems were chosen to immobilize PrA, one including the short chain hydrophilic 6-mercaptohexanol and the other including the long chain, hydrophobic ndecanethiol. Activation of the MUA carboxylic acid tail group appeared to be much more efficient for the mixed SAM containing $\mathrm{C} 6 \mathrm{OH}$. We may explain it by the difference of lengths between the two thiolates making the carboxyl groups protrude out of the layer, which may in turn facilitate its accessibility to reagents in solution [24,37,66] while neighboring methyl groups of the C9CH3 thiolate chains may sterically hinder proper activation.

The influence of the mole fraction of MUA in mixed SAMs containing either C9CH3 or $\mathrm{C6OH}$ was then studied on the chemisorption of PrA. For both diluting thiolates, the highest ratio between adsorbed protein molecules and remaining surface NHS groups was found for $\chi(\mathrm{MUA})_{\text {soln }}=0.25$. Considering the molecular weight of PrA (in the absence of data regarding its size), this fraction of MUA should provide a sufficient number of anchoring points to covalently bind this protein for obvious steric reasons [15,22,24,79].

The amount of adsorbed PrA was much higher on the mixed SAM including C9CH3, despite the initial lower number of surface NHS groups as compared to the SAM including 
$\mathrm{C6OH}$. Physisorption experiments performed on pure SAMs of $\mathrm{C} 9 \mathrm{CH} 3$ and $\mathrm{C} 6 \mathrm{OH}$ monitored by surface IR analysis showed that an appreciable amount of PrA did adsorb to the hydrophobic C9CH3 SAM, while physisorption on $\mathrm{C} 6 \mathrm{OH}$ was poorer, i.e. the area of the amide I+II bands was equal to $8.1 \pm 0.1$ and $14.8 \pm 0.1$ for $\mathrm{C} 6 \mathrm{OH}$ and $\mathrm{C} 9 \mathrm{CH} 3$, respectively. This is in good agreement with previously published works showing higher protein adsorption on hydrophobic surfaces [19,68,80,81]. We may thus infer that binding of PrA to the mixed SAM containing $\mathrm{C6OH}$ was mostly due to the formation of a covalent bond between amines of PrA and surface NHS groups whereas binding to the mixed SAM containing C9CH3 was for its most part due to physisorption.

Non specific binding of BSA onto PrA layers was observed for the mixed SAM including $\mathrm{C6OH}$ but not for the one including $\mathrm{C} 9 \mathrm{CH}$. Given the already high density of PrA molecules onto the latter mixed SAM, binding of BSA was most probably prevented for steric reasons (even though exchange between physically bound PrA and BSA in solution cannot be completely ruled out). Conversely, PrA molecules onto the former mixed SAM (MUA/C6OH) did not form a complete monolayer as deduced from XPS thickness measurement (Table 4), thus allowing BSA to bind non specifically in agreement with other works [68].

Eventually, the ability of the PrA layers to recognize and bind the model antibody rIgG was studied. Again, both PrA layers appeared to behave quite differently. The amount of rIgG bound to PrA on the mixed SAM of MUA and C9CH3 was constant over the range of concentrations of rIgG tested. A very approximate calculation taking into account the respective molecular weights of $\operatorname{rgG}(150 \mathrm{kDa})$ and $\operatorname{PrA}(42 \mathrm{kDa})$ yielded a mole ratio of 0.3 rIgG per PrA. This calculation was done assuming that the area of the amide I+II bands was proportional to the amount of protein molecules. Conversely, the amount of IIgG bound to PrA on the mixed SAM of MUA and $\mathrm{C6OH}$ was dependent on the concentration of rIgG in solution. The same calculation yielded an approximate mole ratio of rIgG per PrA of 1, 1.4 and 2 for the $0.07,0.1$ and $1 \mathrm{~g} / \mathrm{L}$ rIgG solutions, respectively. These figures demonstrate the stronger binding capacity of PrA when immobilized on mixed SAM layers, likely due to reduced steric constraints. Besides that, an increase of $50 \AA$ of the film thickness was measured by XPS, which compares well with the size of mouse IgG $_{1}$ determined by X-ray crystallography [82].

The stoichiometry of rIgG binding was compared to literature data. PrA physisorbed on a QCM gold-coated quartz electrode bound polyclonal IgG at a mole ratio of 0.23 [49], 0.54 [37] or 1.1 [50] whereas PrA covalently bound to various SAMs could bind mouse IgG 1 
at a mole ratio of 0.20 [56] to 0.28 [54]. Finally, a mole ratio of 2.74 was reached on $\operatorname{PrA}$ immobilized on a 3D dextran polymeric layer [50]. Our strategy of PrA immobilization on the mixed SAM of MUA and $\mathrm{C} 6 \mathrm{OH}$ is among the most efficient in terms of IgG recognition and binding capacity.

\section{CONCLUSION}

Mixed self-assembled monolayers of MUA and another thiolate were built on a gold surface; their characterization by PM-IRRAS and XPS revealed an almost linear correlation between solution and surface compositions of mixed SAMs. It also brought into light the marked influence of the "diluting” thiol upon the order of the layer, the mechanism by which Protein A was adsorbed and finally its binding capacity towards a model antibody. Indeed, we found that Protein A was mostly bound by physisorption on the mixed SAM containing decanethiol and its binding capacity towards rabbit IgG was relatively low. Conversely, although the mixed SAM containing 6-mercaptohexanol yielded a lower amount of immobilized Protein A molecules, the resulting bioaffinity platform was much more efficient in terms of antibody binding capacity. One possible important reason is that such a configuration decreased the steric constraints around the IgG binding sites enabling first a better activation and then, the Protein A sensing layer to bind more IgG molecules. These results provide a solid basis for further studies aiming at elaborating sensitive and specific biosensors.

\section{ACKNOWLEDGEMENT}

A. Etcheberry and J. Vigneron are deeply acknowledged for giving us access to their XPS facilities and for discussions.

E.B. thanks IFREMER and CNRS for her PhD grant. 


\section{REFERENCES}

[1] R.G. Nuzzo, L.H. Dubois, D.L. Allara, J. Am. Chem. Soc. 112 (1990) 558.

[2] M.D. Porter, T.B. Bright, D.L. Allara, C.E.D. Chidsey, J. Am. Chem. Soc. 109 (1987) 3559.

[3] C.D. Bain, E.B. Troughton, Y.-T. Tao, J. Evall, G.M. Whitesides, R.G. Nuzzo, J. Am. Chem. Soc. 111 (1989) 321.

[4] G.M. Whitesides, P.E. Laibinis, Langmuir 6 (1990) 87.

[5] A. Ulman, Chem. Rev. 96 (1996) 1533.

[6] J.P. Folkers, P.E. Laibinis, G.M. Whitesides, J. Adhesion Sci. Technol. 6 (1992) 1397.

[7] T. Kakiuchi, M. Iida, N. Gon, D. Hobara, S.-I. Mabayashi, K. Niki, Langmuir 17 (2001) 1599.

[8] D. Hobara, T. Kakiuchi, Electrochem. Commun. 3 (2001) 154.

[9] L. Li, S. Chen, S. Jiang, Langmuir 19 (2003) 3266.

[10] A.V. Shevade, J. Zhou, M.T. Zin, S. Jiang, Langmuir 17 (2001) 7566.

[11] D. Hobara, T. Sasaki, S.-I. Imabayashi, T. Kakiuchi, Langmuir 15 (1999) 5073.

[12] T. Sawaguchi, Y. Sato, F. Mizutani, J. Electroanal. Chem. 496 (2001) 50.

[13] M. El-Deab, T. Ohsaka, Electrochim. Acta 49 (2004) 2189.

[14] S. Chen, L. Li, C.L. Boozer, S. Jiang, J. Phys. Chem. B 105 (2001) 2975.

[15] J. Lahiri, L. Isaacs, B. Grzybowski, J.D. Carbeck, G.M. Whitesides, Langmuir 15 (1999) 7186.

[16] J. Spinke, M. Liley, F.-J. Schmitt, H.-J. Guder, L. Angermaier, W. Knoll, J. Chem. Phys. 99 (1993) 7012.

[17] K.E. Nelson, L. Gamble, L.S. Jung, M.S. Boeckl, E. Naeemi, S.L. Golledge, T. Sasaki, D.G. Castner, C.T. Campbell, P.S. Stayton, Langmuir 17 (2001) 2807.

[18] C.M. Pradier, M. Salmain, Z. Liu, C. Méthivier, Surf. Interface Anal. 34 (2002) 67.

[19] G.B. Sigal, M. Mrksich, G.M. Whitesides, J. Am. Chem. Soc. 120 (1998) 3464.

[20] J. Lahiri, L. Isaacs, J. Tien, G.M. Whitesides, Anal. Chem. 71 (1999) 777.

[21] M. Mrksich, J.R. Grunwell, G.M. Whitesides, J. Am. Chem. Soc. 117 (1995) 12009.

[22] A.J. Guiomar, J.T. Guthrie, S.D. Evans, Langmuir 15 (1999) 1198.

[23] B. Ge, F. Lisdat, Anal. Chim. Acta 454 (2002) 53.

[24] F. Frederix, K. Bonroy, W. Laureyn, G. Reekmans, A. Campitelli, W. Dehean, G. Maes, Langmuir 19 (2003) 4351.

[25] A. Subramanian, J. Irudayaraj, T. Ryan, Biosens. Bioelectron. 21 (2006) 998.

[26] Y.-C. Liu, C.-M. Wang, K.-P. Hsiung, Anal. Biochem. 299 (2001) 130.

[27] J.F. Cabrita, L.M. Abrantes, A.S. Viana, Electrochim. Acta 50 (2005) 2117.

[28] J.W. Lee, S.J. Sim, S.M. Cho, J. Lee, Biosens. Bioelectron. 20 (2005) 1422.

[29] T. Wink, S.J. van Zuilen, A. Bult, W.P. van Bennkom, Analyst 122 (1997) 43R.

[30] F. Caruso, E. Rodda, N. Furlong, J. Colloid Interface Sci. 178 (1996) 104.

[31] I.-N. Chang, J.-N. Lin, J.D. Andrade, J.N. Herron, J. Colloid Interface Sci. 174 (1995) 10.

[32] O. Ouerghi, A. Touhami, A. Othmane, H. Ben Ouada, C. Martelet, C. Fretigny, N. Jaffrezic-Renault, Sens. Actuators B: Chemical 84 (2002) 167.

[33] A.J.C. Eun, L. Huang, F.T. Chew, S.F.Y. Li, S.M. Wong, J. Virol. Methods 99 (2002) 71.

[34] S. Susmel, G.G. Guilbault, C.K. O'Sullivan, Biosen. Bioelectron. 18 (2003) 881.

[35] R. Pei, Z. Cheng, E. Wang, X. Yang, Biosens. Bioelectron. 16 (2001) 355.

[36] X. Su, F.T. Chew, S.F.Y. Li, Anal. Biochem. 273 (1999) 66.

[37] X.-L. Su, Y. Li, Biosens. Bioelectron. 19 (2004) 563. 
[38] K. Wadu-Mesthrige, N.A. Amro, G.-Y. Liu, Scanning 22 (2000) 380.

[39] X. Cui, R. Pei, Z. Wang, F. Yang, Y. Ma, S. Dong, X. Yang, Biosens. Bioelectron. 18 (2003) 59.

[40] C. Boozer, Q. Yu, S. Chen, C.-Y. Lee, J. Homola, S.S. Yee, S. Jiang, Sens. Actuators B: Chemical 90 (2003) 22.

[41] O. Ouerghi, A. Touhami, N. Jaffrezic-Renault, C. Martelet, H. Ben Ouada, S. Cosnier, Bioelectrochem. 56 (2002) 131.

[42] H. Hjelm, J. Sjodahl, J. Sjoguist, Eur. J. Biochem. 57 (1975) 395.

[43] R. Lindmark, K. Thoren-Telling, J. Sjoquist, J. Immunol. Methods 62 (1983) 1.

[44] B. Lu, M.R. Smyth, R. O'Kennedy, Analyst 121 (1996) 29 R.

[45] J. Quinn, P. Patel, B. Fitzpatrick, B. Manning, P. Dillon, S. Daly, R. O'Kennedy, M.

Alcocer, H. Lee, M. Morgan, K. Lang, Biosens. Bioelectron. 14 (1999) 587.

[46] B.S. Attili, A.A. Suleiman, Anal. Lett. 28 (1995) 2149.

[47] B. Konig, M. Gratzel, Anal. Chem. Washington 66 (1994) 341.

[48] B. Konig, M. Gratzel, Anal. Chim. Acta 309 (1995) 19.

[49] A.E. Gerdon, D.W. Wright, D.E. Cliffel, Anal. Chem. 77 (2005) 304.

[50] H.-C. Lu, H.-M. Chen, Y.-S. Lin, J.-W. Lin, Biotechnol. Prog. 16 (2000) 116.

[51] M. Michalzik, J. Wendler, J. Rabe, S. Buttgenbach, U. Bilitewski, Sens. Actuators B: Chemical 105 (2005) 508.

[52] G.-Y. Shen, H. Wang, T. Deng, G.-L. Shen, R.-Q. Yu, Talanta 67 (2005) 217.

[53] B. Zuo, S. Li, Z. Guo, J. Zhang, C. Chen, Anal. Chem. 76 (2004) 3536.

[54] P. Skladal, Z. Jilkova, I. Svoboda, V. Kolar, Biosens. Bioelectron. 20 (2005) 2027.

[55] J. Yakovleva, R. Davidsson, M. Bengtsson, T. Laurell, J. Emneus, Biosens. Bioelectron. 19 (2003) 21.

[56] J. Pribyl, M. Hepel, J. Halamek, P. Skladal, Sens. and Actuators B: Chemical 91 (2003) 333.

[57] M.C. Millot, F. Martin, D. Bousquet, B. Sebille, Y. Levy, Sens. Actuators B Chemical 29 (1995) 268.

[58] W. Lee, D.-B. Lee, B.-K. Oh, W.H. Lee, J.-W. Choi, Enzyme Microbial Technology 35 (2004) 678.

[59] N.M. Grubor, R. Shinar, R. Jankowiak, M.D. Porter, G.J. Small, Biosens. Bioelectron. 19 (2004) 547.

[60] S. Babacan, P. Pivarnik, S. Letcher, A.G. Rand, Biosens. Bioelectron. 15 (2000) 615.

[61] J.H. Scofield, J. Electron Spectrosc. Relat. Phenom. 8 (1976) 129.

[62] B.J. Barner, M.J. Green, E.I. Saez, R.M. Corn, Anal. Chem. 63 (1991) 55.

[63] T. Buffeteau, B. Desbat, J.M. Turlet, Appl. Spectrosc. 45 (1991) 380.

[64] C.D. Bain, G.M. Whitesides, J. Am. Chem. Soc. 110 (1998) 6560.

[65] B.L. Frey, C.E. Jordan, S. Kornguth, R.M. Corn, in Anal. Chem., 67 (1995) 4452.

[66] N. Patel, M.C. Davis, M. Hartshorne, R.J. Heaton, C.J. Roberts, S.J.B. Tendler, P.M. Williams, Langmuir 13 (1997) 6485.

[67] R.V. Duevel, R.M. Corn, Anal. Chem. 64 (1992) 337.

[68] V. Silin, H. Weetall, D.J. Vanderah, J. Colloid Interface Sci. 185 (1997) 94.

[69] D.G. Castner, K. Hinds, D.W. Grainger, Langmuir 12 (1996) 508.

[70] C.J.P. Boonaert, Y.F. Dufrêne, S.R. Derclaye, P.G. Rouxhet, Colloids Surf. B: Biointerfaces 22 (2001) 171.

[71] E.B. Troughton, C.D. Bain, G.M. Whitesides, R.G. Nuzzo, D.L. Allara, M.D. Porter, Langmuir 4 (1998) 365. 
[72] H.L. Shuttleworth, C.J. Duggleby, S.A. Jones, T. Atkinson, N.P. Minton, Gene 58 (1987) 283.

[73] M. Wirde, U. Gelius, L. Nyholm, Langmuir 15 (1999) 6370.

[74] M. Gore, G, A.G. Popplewell, W.F. Ferris, M. Scawen, T. Atkinson, Biochem. Soc. Trans. 20 (1992) 289S.

[75] P.E. Laibinis, C.B. Chain, G.M. Whitesides, J. Phys. Chem. B 95 (1991) 7017.

[76] K.D. Truong, P.A. Rowntree, J. Phys. Chem. B 100 (1996) 19917.

[77] S. Chen, L. Li, C.L. Boozer, S. Jiang, Langmuir 16 (2000) 9287.

[78] E. Briand, M. Salmain, J.M. Herry, H. Perrot, C. Compère, C.M. Pradier, Biosens. Bioelectron., 2006, in press.

[79] L. Huang, G. Reekmans, D. Saerens, J.-M. Friedt, F. Frederix, L. Francis, S. Muyldermans, A. Campitelli, C.V. Hoof, Biosens. Bioelectron. 21 (2005) 483.

[80] I.C. Gonçalves, M.C.L. Martins, M.A. Barbosa, B.D. Ratner, Biomaterials 26 (2005) 3891.

[81] M.C.L. Martins, B.D. Ratner, M.A. Barbosa, J. Biomed. Mat. Res. A 67A (2003) 158.

[82] L.J. Harris, E. Skaletsky, A. McPherson, J. Mol. Biol. 275 (1998) 861. 
Table 1. Covalent binding of PrA on various mixed SAMs of MUA and C9CH3. PM-IRRAS analysis of the gold surfaces

\begin{tabular}{ll}
\hline$\chi(\text { MUA })_{\text {soln }}$ & Ratio of the amide I+II bands area over the $1746 \mathrm{~cm}^{-1}$ band area \\
\hline 0.25 & 14.1 \\
0.5 & 10.1 \\
0.75 & 8.8 \\
1 & 5.5 \\
\hline
\end{tabular}

Table 2. Relative amount of the different types of $\mathrm{C}$ atoms in the mixed MUA / C6OH SAM $\left(\chi(\mathrm{MUA})_{\text {soln }}=0.25\right)$ as measured on the XPS C 1s high resolution spectrum (fig. 8a) and calculated from the chemical composition of the film assuming $\chi(\mathrm{MUA})_{\text {surf }}=\chi(\mathrm{MUA})_{\mathrm{soln}}$.

\begin{tabular}{lll}
\hline Carbon type & $\begin{array}{l}\text { Relative intensity of the C 1s } \\
\text { component }\end{array}$ & $\begin{array}{l}\text { Calculated relative } \\
\text { amount }\end{array}$ \\
\hline $\mathrm{C}-\mathrm{C}, \mathrm{C}-\mathrm{H},(\mathrm{BE}=285.0 \pm 0.2 \mathrm{eV})$ & $67 \%$ & $83 \%$ \\
$\mathrm{C}-\underline{\mathrm{C}}-\mathrm{O},(\mathrm{BE}=286.5 \pm 0.2 \mathrm{eV})$ & $24 \%$ & $10 \%$ \\
$\mathrm{O}-\mathrm{C}=\mathrm{O},(\mathrm{BE}=289.0 \pm 0.2 \mathrm{eV})$ & $9 \%$ & $7 \%$
\end{tabular}

Table 3. Relative amount of the different types of $\mathrm{C}$ atoms in the film of PrA as measured on the XPS C 1s high resolution spectrum (Fig. 8b) and calculated from the chemical composition of PrA

\begin{tabular}{llll}
\hline Carbon type & $\begin{array}{l}\text { Calculated number } \\
\text { of C atoms in PrA }\end{array}$ & $\begin{array}{l}\text { Calculated relative } \\
\text { amount in PrA }\end{array}$ & $\begin{array}{l}\text { Relative intensity of } \\
\text { the C 1s contribution }\end{array}$ \\
\hline $\begin{array}{l}\mathrm{C}-\mathrm{C}, \mathrm{C}-\mathrm{H} \\
(\mathrm{BE}=284.8 \pm 0.2 \mathrm{eV})\end{array}$ & 704 & $36 \%$ & $40 \%$ \\
$\begin{array}{l}\mathrm{C}-\mathrm{C}-\mathrm{N} \\
(\mathrm{BE}=285.8 \pm 0.2 \mathrm{eV})\end{array}$ & 551 & $28 \%$ & $17 \%$ \\
$\begin{array}{l}\mathrm{C}-\mathrm{C}-\mathrm{O}, \mathrm{C} \text { arom. } \\
(\mathrm{BE}=286.8 \pm 0.2 \mathrm{eV})\end{array}$ & 147 & $7 \%$ & $17 \%$ \\
$\begin{array}{l}\mathrm{O}-\mathrm{C}=\mathrm{O}, \mathrm{N}-\mathrm{C}=\mathrm{O} \\
(\mathrm{BE}=288.6 \pm 0.2 \mathrm{eV})\end{array}$ & 572 & $29 \%$ & $26 \%$ \\
\hline
\end{tabular}

Table 4. XPS Au $4 \mathrm{f}_{7 / 2}$ peak intensity and calculated average layer thickness after successive steps of functionalization

\begin{tabular}{lllll}
\hline & bare & Mixed MUA/C6OH SAM & PrA & rIgG \\
\hline $\mathrm{I}\left(\mathrm{Au} \mathrm{4f_{7/2 } )}\right.$ & 441664 & 362933 & 299928 & 91717 \\
$\mathrm{~d}(\mathrm{~nm})$ & - & 0.82 & 1.63 & 6.60 \\
\hline
\end{tabular}




\section{Figure captions}

Figure 1: PM-IRRAS analysis of mixed SAMs of MUA with a) C9CH3; b) C5CH3; c) $\mathrm{C} 11 \mathrm{OH}, \mathrm{d}) \mathrm{C} 6 \mathrm{OH}\left(\chi(\mathrm{MUA})_{\text {soln }}=0.5\right)$.

Figure 2: a) Area of the $v \mathrm{C}=\mathrm{O}$ band on the surface IR spectra as a function of $\chi(\mathrm{MUA})_{\text {soln }}$ for mixed SAMs of MUA and C9CH3; b) vC-H region of the surface IR spectra of mixed SAMs of MUA and C9CH3, $\chi(\mathrm{MUA})_{\text {soln }}=0.25,0.50,0.75$ and 1 corresponding to a, b, c and d respectively.

Figure 3: Normalized $\mathrm{O}$ 1s/Au $4 \mathrm{f}$ ratio as a function of $\chi(\mathrm{MUA})_{\text {soln }}$ for mixed SAMs of MUA and $\mathrm{C} 9 \mathrm{CH} 3$.

Figure 4: a) Area of the $v \mathrm{C}=\mathrm{O}$ band on the surface IR spectra as a function of $\chi(\mathrm{MUA})_{\text {soln }}$ for mixed SAMs of MUA and $\mathrm{C} 6 \mathrm{OH}$; b) $v \mathrm{C}-\mathrm{H}$ region of the surface IR spectra of mixed SAMs of MUA and $\mathrm{C6OH}, \chi(\mathrm{MUA})_{\text {soln }}=0,0.25,0.50,0.75$ and 1 corresponding to a, b, c, d and e respectively.

Figure 5: PM-IRRAS analysis of mixed SAMs of MUA and C9CH3 $\left(\chi(\mathrm{MUA})_{\text {soln }}=0.25\right)$ after treatment by a) NHS and EDC; b) Protein A; c) ethanolamine

Figure 6: PM-IRRAS analysis of mixed SAMs of MUA and C6OH $\left(\chi(\mathrm{MUA})_{\text {soln }}=0.25\right)$ after treatment by a) NHS and EDC; b) Protein A; c) ethanolamine

Figure 7: IR peptide region of the gold surfaces after PA binding, blocking by BSA and antigen recognition; the initial thiolate solutions were $\mathrm{MUA} / \mathrm{C} 6 \mathrm{OH}$ (Fig. 7,a) or $\mathrm{MUA} / \mathrm{C} \mathrm{CH}_{3}$ (Fig. 7,b) with $\chi(\mathrm{MUA})_{\text {soln }}=0.25$.

Figure 8: High resolution $C$ 1s spectra of the gold surface covered (a) with the mixed SAM of MUA and $\mathrm{C} 6 \mathrm{OH}\left(\chi(\mathrm{MUA})_{\text {soln }}=0.25\right)$; (b) after binding of PrA.

Figure 9: High resolution $N$ 1s spectra of the gold surface covered (a) with the mixed SAM of MUA and $\mathrm{C6OH}\left(\chi(\mathrm{MUA})_{\text {soln }}=0.25\right)$; (b) after binding of PrA; (c) after recognition of rIgG.

Scheme 1: Activation of the MUA terminal acid groups and PrA binding

Scheme 2: Schematic representation of the PrA layer after "blocking” by BSA 


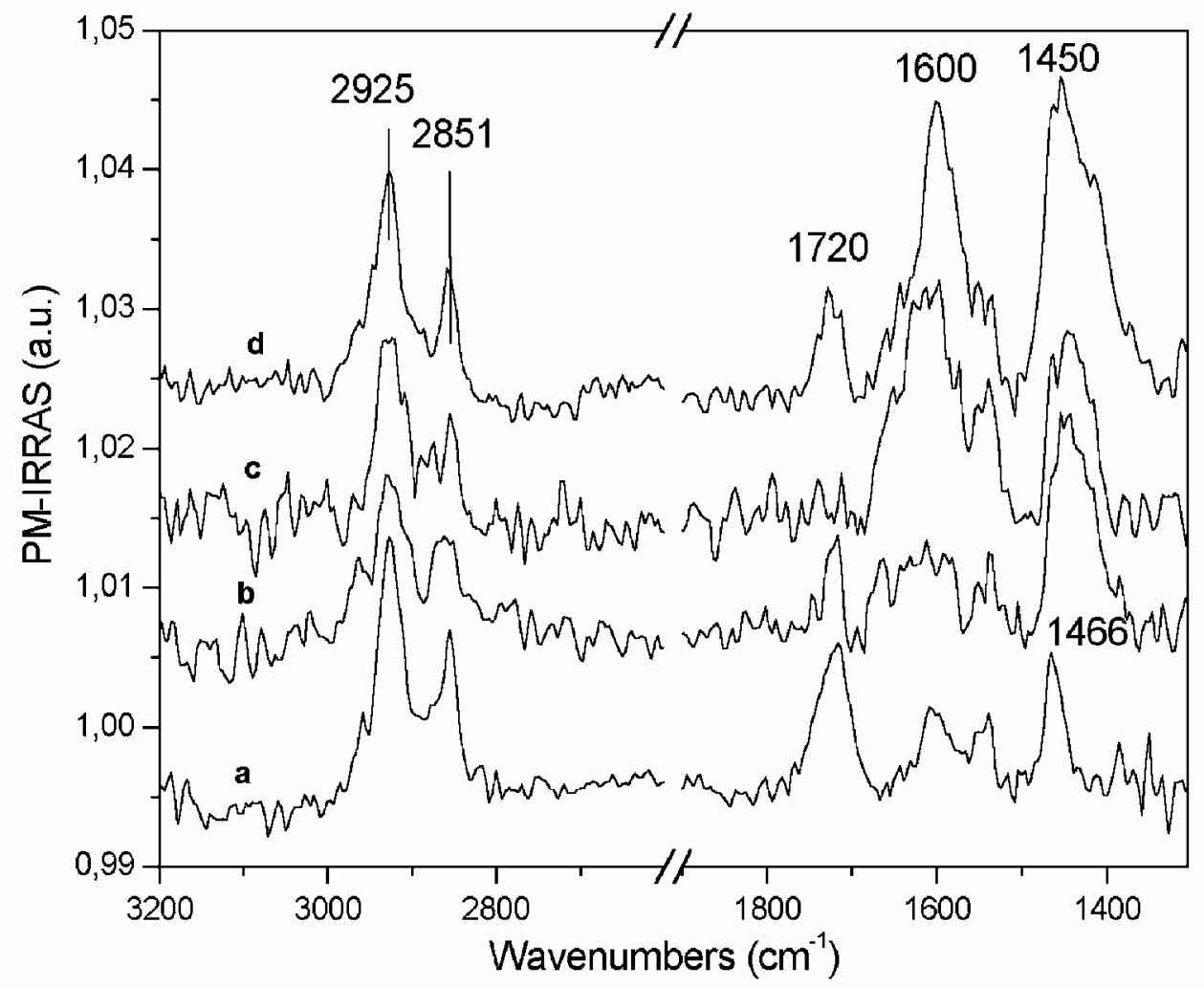

Figure 1

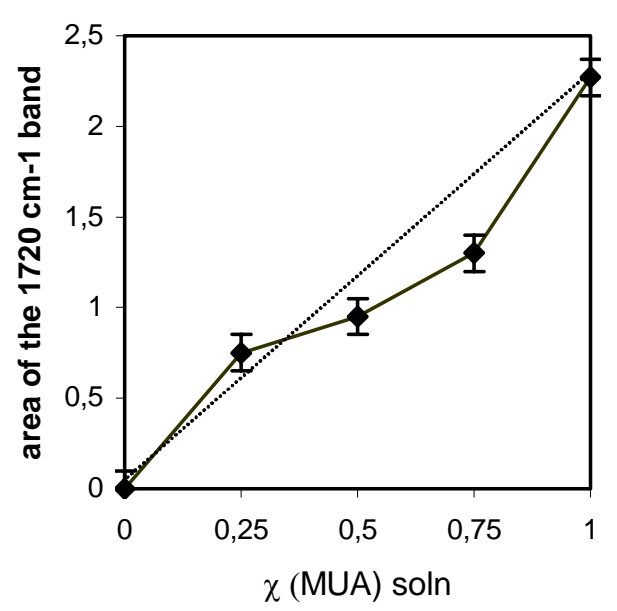

Figure 2a

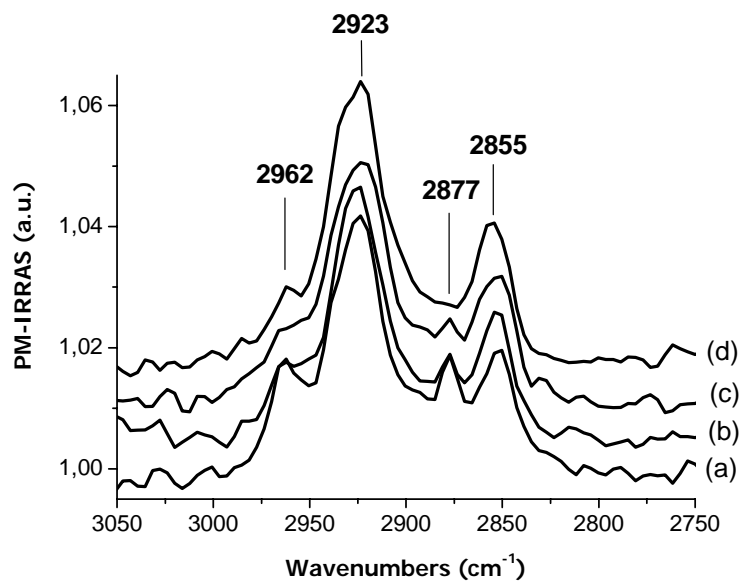

Figure 2b 


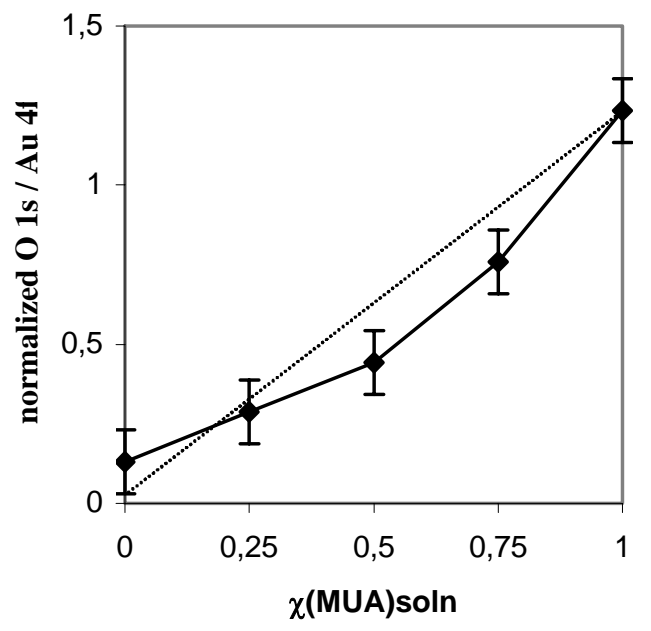

Figure 3

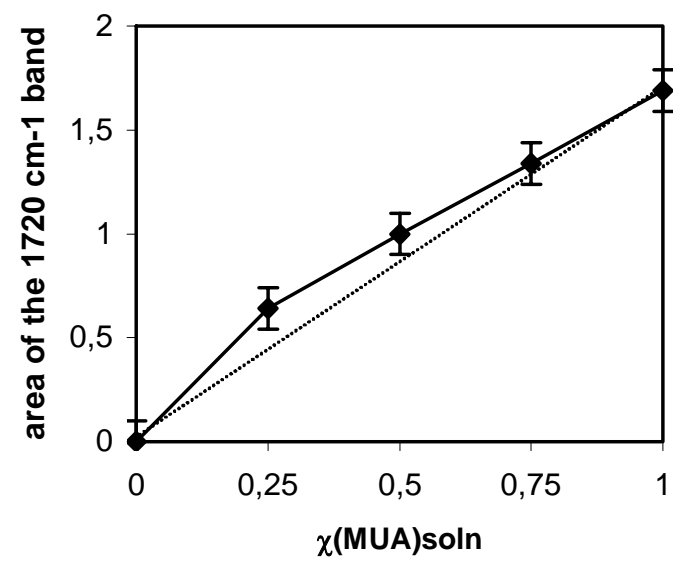

Figure 4a

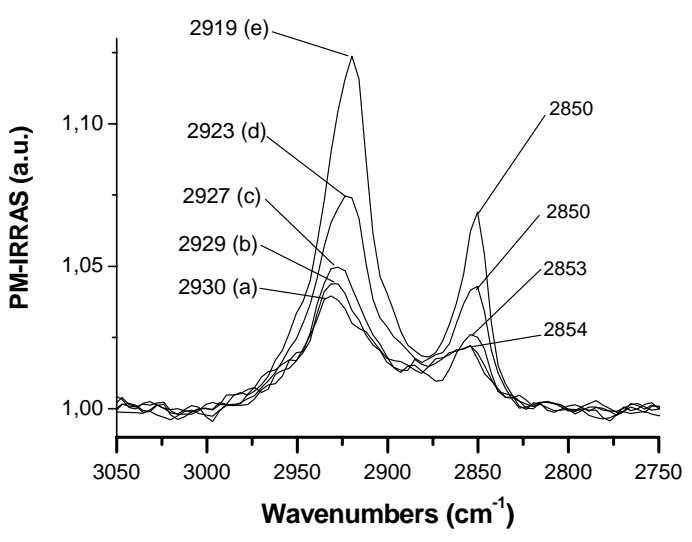

Figure 4b 


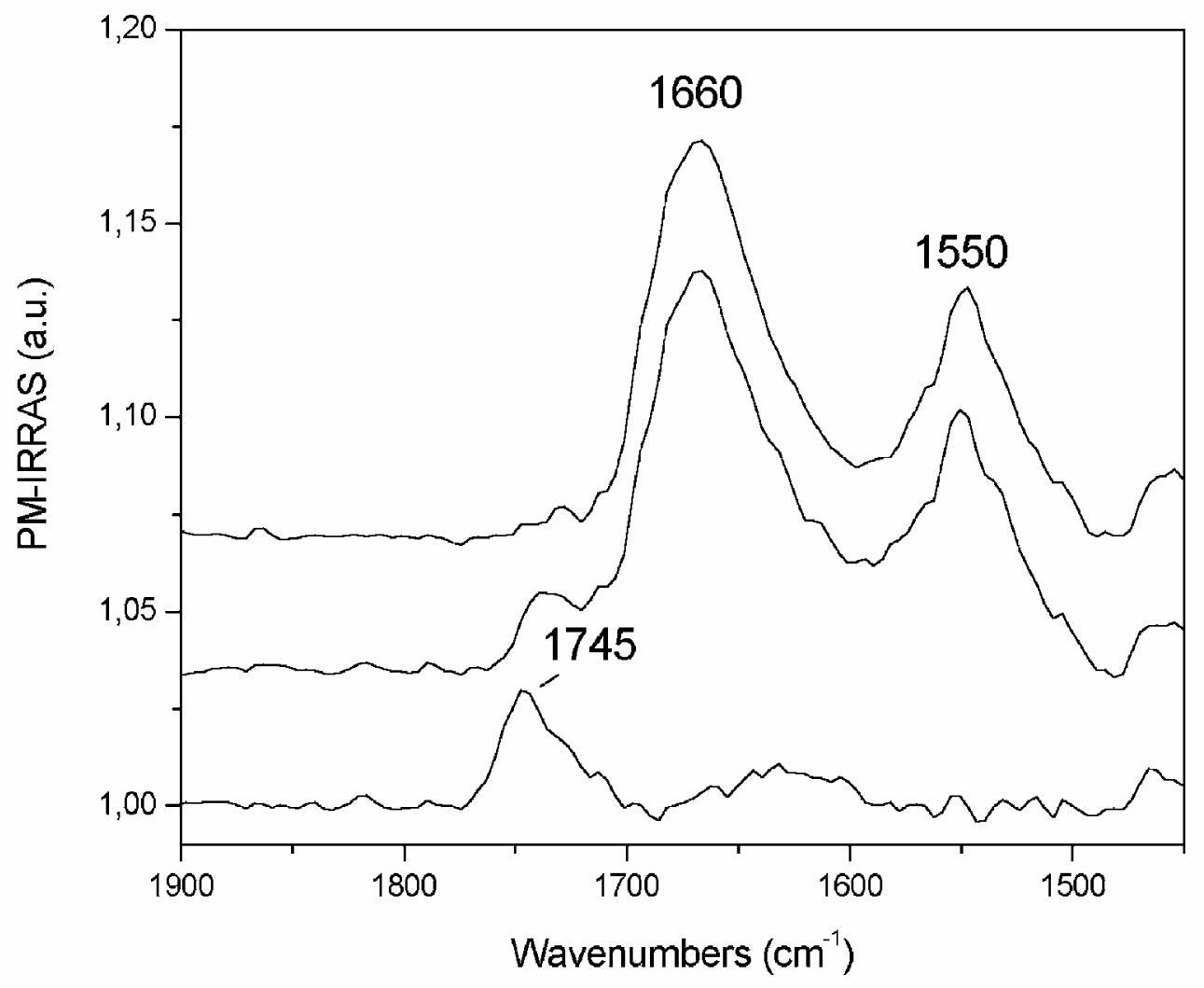

Figure 5 


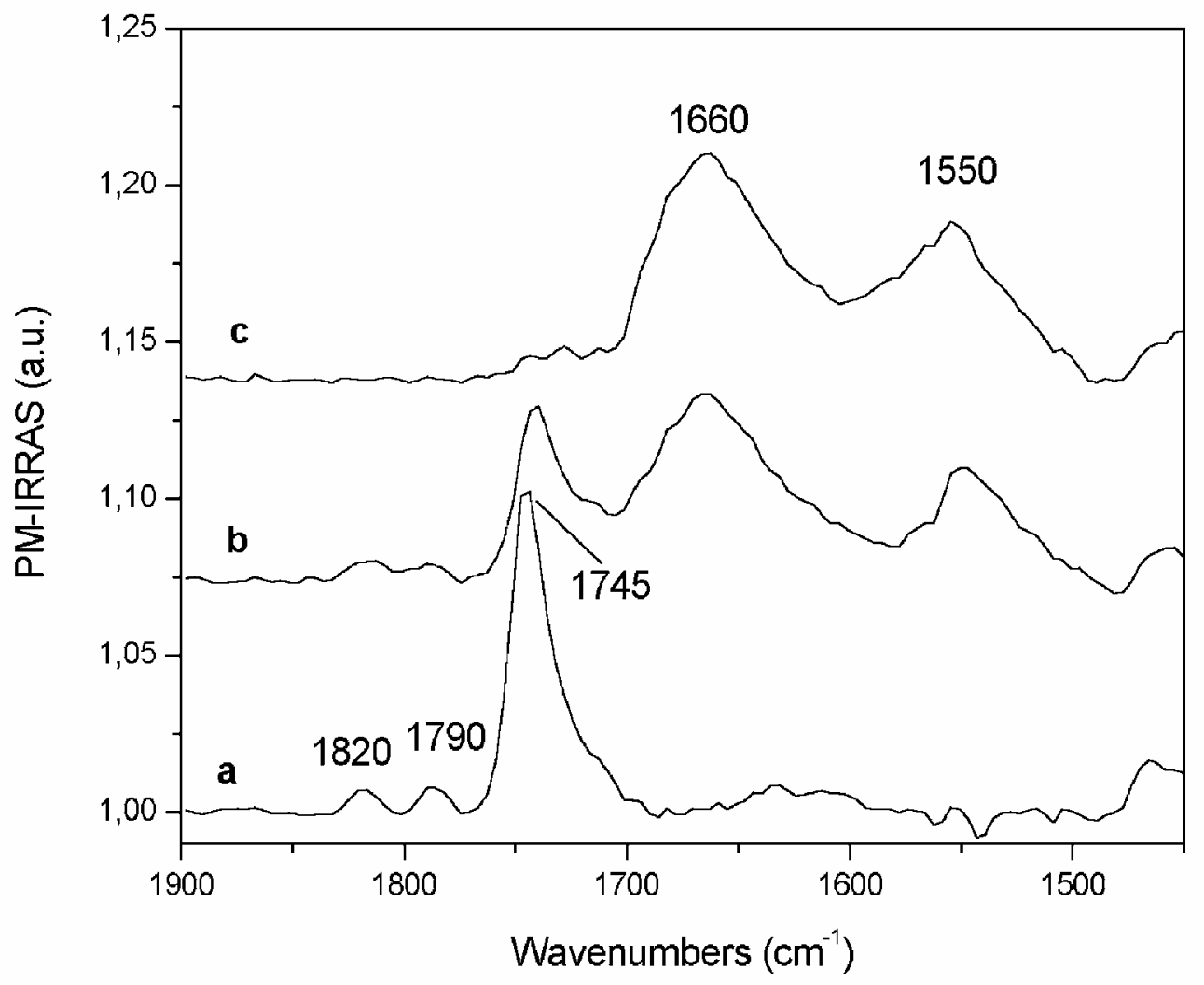

Figure 6

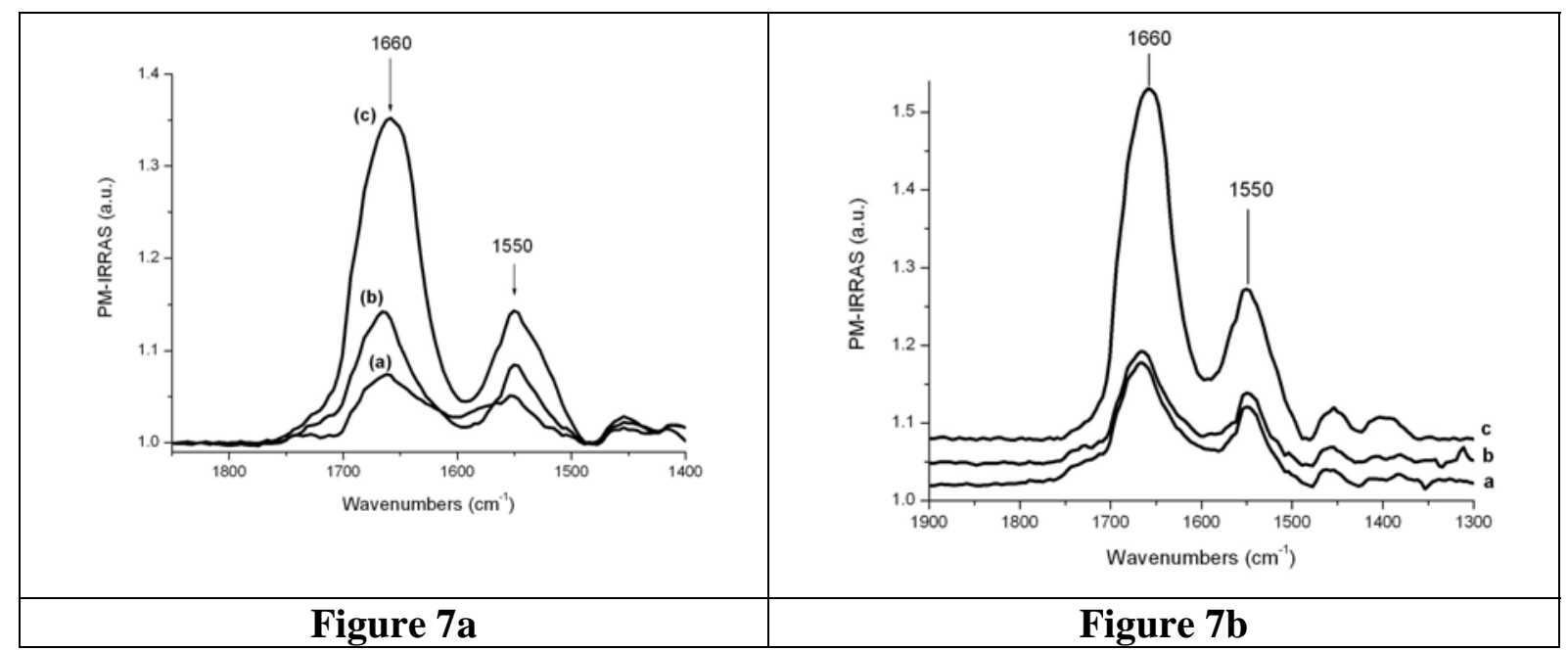




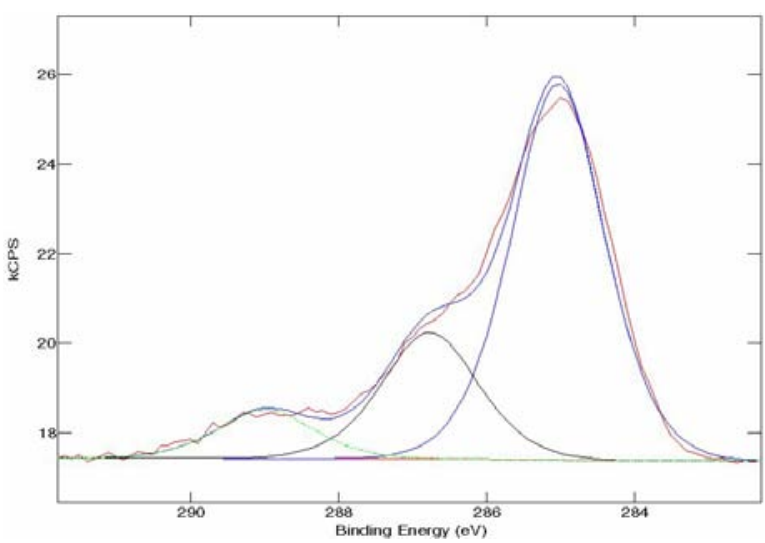

Figure 8a

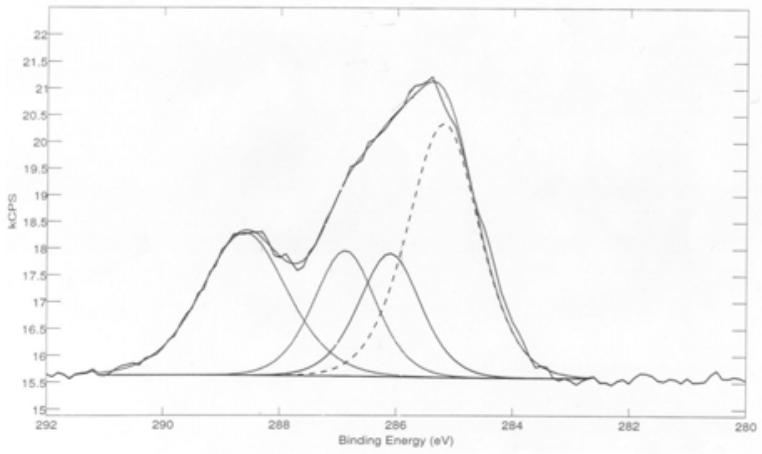

Figure 8b

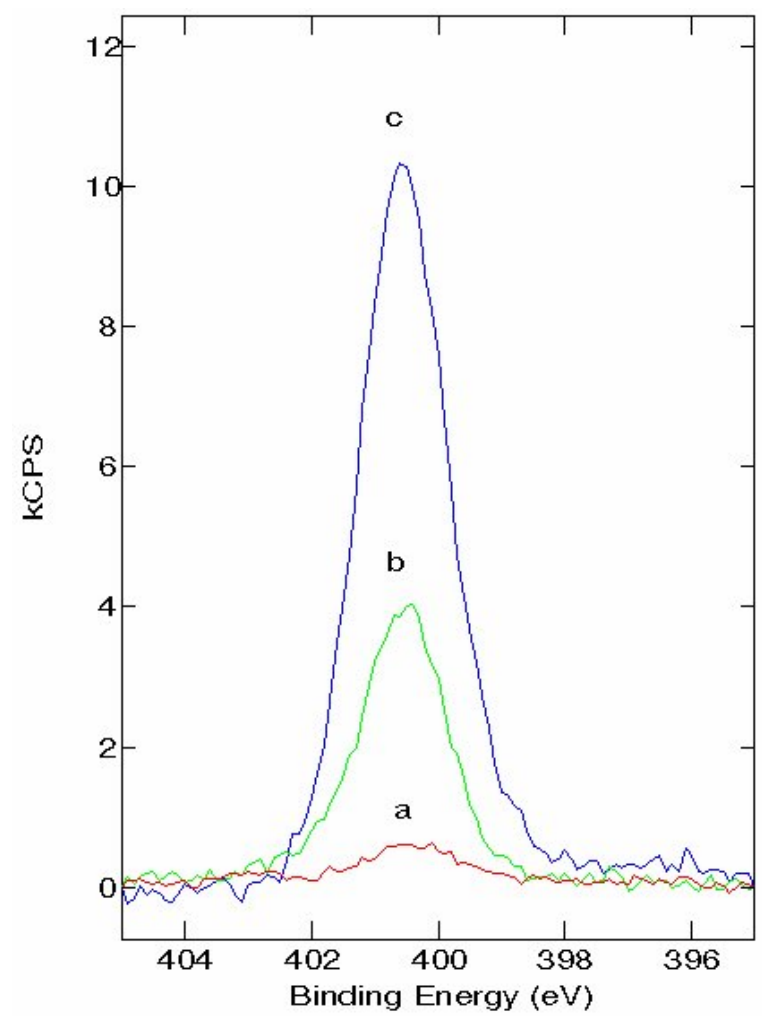

Figure 9 


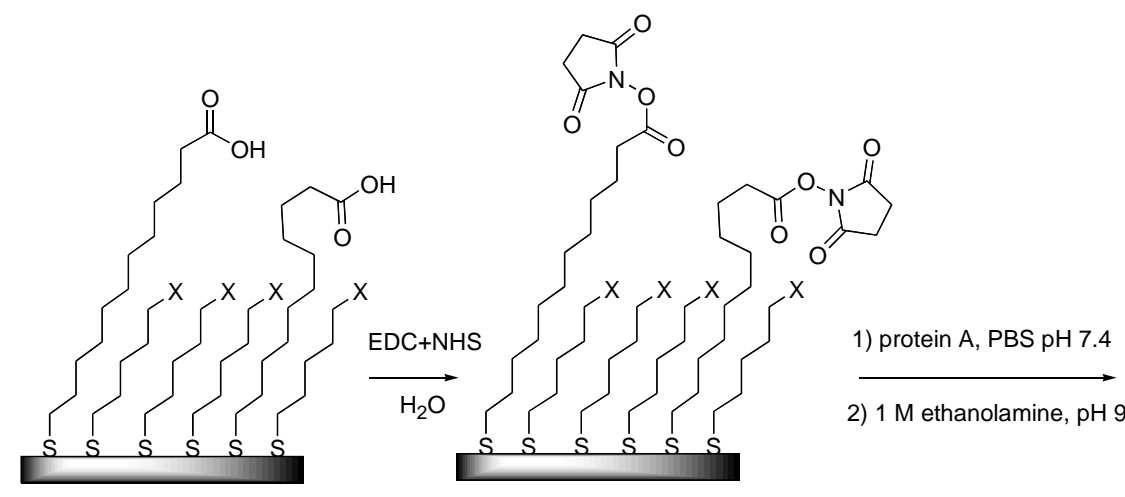

protein $A$

$\mathrm{X}=\mathrm{OH}$ or $\left(\mathrm{CH}_{2}\right)_{2}-\mathrm{CH}_{3}$

Scheme 1

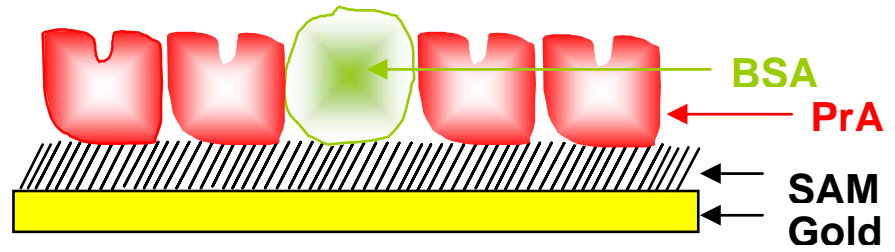

Scheme 2 